\title{
Reflection on Development of Sports Humanistic Sociology Disciplines and the Strategies
}

\author{
Yuandeng You \\ Pukyong National University \\ Busan, South Korean
}

\author{
Sunho Mun \\ Pukyong National University \\ Busan, South Korean
}

\begin{abstract}
In recent years, China's sports humanistic sociology disciplines witness a vigorous development, and have made great achievements. With the multidisciplinary cross and penetration, the research scope of sports humanistic sociology disciplines has expanded gradually, but at the same time, there have been some new problems. This paper has studied on and made reflections on the problems that emerge in the development of sports humanistic sociology disciplines, and put forward the corresponding scientific development strategy.
\end{abstract}

Keywords-sports humanistic sociology disciplines; development; reflection; strategy

\section{INTRODUCTION}

The position of sports humanities and social sciences in scientific discipline has not been established until 1997. In the development in nearly two decades, it is a comfort to see the fruitful achievements that have been made, and a set of scientific theory system and application mode has been formed on the whole. However, we shall not be satisfied with the status quo, as there are still many problems to be resolved. We should view the problem with long-term vision, so as to seek further development for sports humanities and sociology.

\section{CURRENT SituAtion OF CHINA'S SPORTS HUMANITIES AND SOCIOLOGY}

\section{A. Sports Humanistic Sociology Has Achieved Fruitful Results}

In the recent two decades since the disciplines of sports humanities and social sciences was officially established in 1997, sports and social humanities has developed rapidly and obtained fruitful results. Workers of sports humanities and social sciences publish academic journals publicly at home and abroad, and numerous academic monographs have been published. Among which, sports humanistic sociology and economics, management science, fine arts combine with each other, having formed many diversified branch disciplines, laying a good foundation for the development of sports humanistic sociology.

\section{B. Rudiment of Sports Humanities and Social Sciences Disciplines Has Been Basically Formed}

The formation of a new sports discipline needs the nature of the discipline, object of the discipline, discipline research scope, research methods, knowledge structure and other basic elements. Some scholars believe that sports humanistic sociology is a discipline with strong comprehensiveness, and it is developed based on two basic disciplines, namely the sports science and humanistic sociology. Humanistic sociology provides sufficient theoretical support, while sports science provides more theoretical materials. Therefore, the combination of the two makes the sports humanistic sociology a new discipline giving consideration to both theory and practice, serving the practice of sports, moreover, it also makes treasury of humanities and social sciences more abundant from the perspective of sports. However, there are other scholars believe that, sports humanistic sociology is a marginal discipline that has its own unique property, but relays on sociology and sports science. All in all, sports humanistic sociology serves the development of society and human progress, being the product of social development. At present, the research object of sports humanistic sociology has been basically clear. The researchers hold the opinion that, the research contents of sports humanistic sociology should be various humanistic and social phenomena generated in the sports, to research the nature and development law of these phenomena. This is the emphasis of the study on sports humanistic sociology. Meanwhile, there are also some scholars believe that the research object of sports humanistic sociology is the phenomenon of sports and its development law, as well as the relationship between the phenomenon and the law.

Sports humanistic sociology research methods and theoretical system are also being formed. The methodological system of sports humanistic sociology is divided into three levels, namely, general methodology, special methodology and individual methodology. As for sports humanistic sociology, general methodology refers to the common, general characteristics and law. In general, these are the characteristics shared by all the objects, so it is called the general methodology. Special methodology refers to the special areas and special methods of research objects, for example, as for the sports training fields and sports training direction, although they are applicable to the general methodology, some are only directed against the special methods summarized from sports training due to its practical specificity. It is characterized by specificity, but it is quite narrow, which cannot be widely used in multiple disciplines, being hard to be widely applied as it has strong individual experience. Nowadays, with the extensive application of social survey methods, the research methods of humanities and social sciences are gradually 
matured, which will become an important source for collecting sports social information. With the improvement of science and technology as well as the popularization of network, the consciousness of constructing social survey network has been formed.

The academic disciplinary system of sports humanities and social sciences has been initially established. In addition, at present, researchers have built the system of sports humanistic sociology disciplines, which mainly unfold from humanistic phenomena and social phenomena based on the dichotomy of research objects. In other words, to construct sports humanities and social sciences into a plane field with intersection of humanities and social sciences.

The discipline knowledge structure and discipline contents of sports humanistic sociology have been initially established. Currently, researchers have reached a consensus on the viewpoint that the knowledge structure and discipline contents of sports humanistic sociology unfolded based on three-level disciplines. If viewed from the perspective of the classification of two-level sports disciplines, then sports humanistic sociology disciplines contains more extensive extents, and we cannot cover all of them. Therefore, at present, the researchers only select a number of familiar, mature and relatively more important disciplines to research, thus constitutes a set of knowledge structure and discipline contents relatively recognized by most people.

\section{Research Field and Research Scope of Sports Humanistic Sociology Continue to Expand}

20 years ago, due to the backwardness of the level of sports and the limitation of sports knowledge, the research field of China's Sports Humanities and Social Sciences Institute was narrow and the research contents were relatively simple. Nowadays, scholars have gradually recognized the influence of social environment and various elements on sports, so researchers have integrated other fields and broader social background into the research of sports humanistic sociology disciplines, which has obvious promotion and restriction effect on sports. Therefore, the contemporary scholars often research sports social humanities disciplines by putting put them into the broad background, which is conducive to discover many phenomena and problems that have not been paid attention to, bringing new topics to the research of sports social humanities. Especially since the reform and opening up, China's economic development level has improved rapidly, with great progress having been made in economic, cultural, social and other aspects, which enables sports to have more opportunities to further deepen in more research directions, creating the discipline of human sociology into a pluralistic advantage discipline.

After nearly two decades' research by the researchers, we have realized that a subject is not a single and independent one, but one that has a high degree of comprehensiveness, the same is true to sports. In order to explore the theory and practice of sports humanistic sociology, it is desirable to start from other various fields, integrate modern science, so that sports humanistic sociology has its strong theoretical basis.
Modern humanities and social sciences have been introduced into sports science, enabling the subject of sports to reflect different fields of social and cultural phenomena from different levels and different directions, which has laid a solid foundation for sports humanistic sociology research. Humanities and social sciences disciplines play an indelible role in sports research. It not only can strengthen the theoretical basis and cognitive ability of sports humanities and social sciences research, but also can improve the cognitive level of sportsmen toward sports science research, making the research on sports humanities and social sciences disciplines more in-depth and extensive. At present, the study on sports humanistic sociology is mainly carried out in the following fields, namely, relationship between sports and economic and social development, the basic theory and disciplinary system of sports humanities and social sciences, the development of sports undertakings reform and development, theory and practice of sports industry, sports management system reform, theory and practice for the implementation of Olympic Glorious Program, theory and practice for the implementation of the National Fitness Program.

\section{A number of Branch Disciplines Have Been Created}

With the extensive popularization of physical education curriculum in our country, the teaching content of sports practice has been running and the mechanism has been improved accordingly. The research and compilation of sports humanities and social sciences are also expanding. It gradually combines with sociology, economics, politics, history, communication and other branch disciplines, showing the characteristics of multiple disciplines crossing with each other. In the National Science Foundation (NSF) sports project research, the proportion of cross-disciplinary researches account for nearly half of the total projects. It involves in the fields of philosophy, economics, law, sociology, demography, behavior, ethnology, etc., with obvious research trend of discipline penetration and cross.

Disciplines vary from one to another, but there is also a high degree of comprehensiveness. Contemporary social and economic science and technology develop rapidly, the previous field of sports humanities and social sciences has been unable to meet the needs of development, and there is a demand for renewed and more perfect network knowledge framework. As a result, a number of other branch disciplines on the basis of sports humanities and social sciences have emerged, such as sports economics, sports sociology, sports ethics, sports law, and all these branches have become a more powerful support of sports humanistic sociology.

\section{E. Learn from Foreign Research Achievement Actively}

While actively studying sports humanistic sociology disciplines, Chinese scholars have made remarkable achievements in many aspects of introducing foreign sports humanities and social fields. Various editorial and publishing houses have organized to translate and publish many foreign works, which plays a huge role in promoting China's sports humanistic sociology into international academic front. 


\section{F. Applied Research Trend Is Obvious}

In recent years, China's sports humanistic sociology research mainly focuses on the new proposed problems and fields from sports practice. Researchers are no longer only focus on theoretical research as in the past, but pay more attention to the application of sports humanities and social sciences in practice. Great progress have been made in sports application research, such as sports development strategy research, sports system reform research, sports socialization research, sports industrialization research, competitive sports' sustainable development research and other aspects, which shows that the development of China's sports undertakings is not limited to the spread of theoretical knowledge, but pays more attention to practice and research. This can also be seen from the National Social Science Fund and the General Administration of Sport in the planning of sports social science projects.

\section{PROBLEMS IN THE DEVELOPMENT OF SPORTS HuMANISTIC SOCIOLOGY IN CHINA}

\section{A. Disciplinary Basic Theory of Sports Humanistic Sociology Is Weak}

Although the sports humanistic sociology has been developed for nearly two decades, and has become a national grade-2 subject, we must recognize the sports humanistic sociology has the nature of substantive, having no its own place in reality. China's scholars have been discussing in the theoretical research of sports humanistic sociology. But so far, it is still unclear as for the formation of symbolic elements of new disciplines, such as the concept system of sports humanistic sociology and research category. Which theories does sports humanistic sociology contain? At present, researchers have not systematically extracted. Therefore, on the whole, the disciplinary basic theory of China's sports humanistic sociology is still relatively weak, and many fields are in a stage of progress. But our own theoretical system has not been formed, as we just blindly use foreign theoretical research achievements for reference.

\section{B. Disciplinary Framework of Three-Dimensional Network Structure Has Not Been Formed}

With the development of modern scientific system structure and classification, the subject system of sports humanistic sociology should follow closely, which cannot be separated from the structure and basic context of sports science system, and cannot be divorced from the actual situation of Chinese sports reform and development. If we rely solely on the researchers' baseless logical reasoning or arbitrary construction of disciplinary system, there will be no foundation for discipline system construction. Modern scientific system and modern sports science system should be a multi-level and multi-form three-dimensional network structure under the reform of China's education system. It should be an open, continuous network structure with potential for development. Some scholars believe that the disciplinary system should have two basic categories. One is academic disciplinary system, and the second is the subject system of teaching. From the perspective of disciplinary construction, dissemination application and renewal process, especially from the relationship between academic research and school education, academic disciplinary system and teaching subject system are complementary and interrelated. Therefore, in addition to the task of academic discipline construction, sports humanities and social sciences should also pay attention to talent training and school discipline construction. The construction of academic disciplines and school discipline is a good form in start-up phase. There are also some other views that disciplinary system is an organic combination of system structure and structural system. The so-called system structure refers to the composition of theoretical knowledge units, how the theoretical units form a unified entirety according to certain layered structure and logical structure. Structural characteristics refer to the internal characteristics of a system, rather than external ones. Structural system refers to that although some branch disciplines are independent of each other, they complement each other, building the overall discipline jointly. Only the two are unified, can an organic entity with clear layers and precise structure, that is, the disciplinary system of sports humanistic sociology disciplines, be formed.

\section{Unbalanced Development of Branch Disciplines}

In the branch disciplines of sports humanistic sociology, some disciplines develop rapidly, having formed one set of its own disciplines and systems, such as sports sociology, sports economics and others. But some of the disciplines started quite late or develop slowly, requiring vigorous support, such as sports, anthropology, sports entertainment and leisure theory need to achieve breakthrough progress, such as sports history, sports aesthetics and so on. There are some disciplines need to get rid of the shackles of the previous teaching for sports, to seek new breakthroughs. Such phenomenon of unbalanced development in branch disciplines of sports humanistic sociology has hindered the further development of China's sports humanities and social sciences.

\section{DEVELOPMENT STRATEGY OF CHINESE SPORTS HUMANISTIC SOCIOLOGY}

\section{A. To Strengthen the Ontological Theoretical Research on Sports Humanistic Sociology}

A mature subject needs to answer the following three questions, namely "what, why, how to do". Therefore, it is necessary to clarify the definition and position of disciplines, the purpose of discipline research, task objects, etc. to conduct basic positioning of disciplines, which is an important indicator of maturity of the discipline. At present, the development of sports humanities and social sciences in China needs breakthroughs from two aspects, one is the scientific theoretical system of sports humanistic society, including the subject positioning, research object, research field and research task of sports humanistic sociology. Second, the disciplinary system of sports humanistic sociology, shall conduct a comprehensive, overall and deeper rational analysis of sports, humanities and sociology, to have a pioneering and forwardlooking vision. 


\section{B. To Create A Good Atmosphere for the Development of Sports Humanistic Sociology Disciplines}

Although sports social humanities has developed for 20 years, there are too few scholars who can research on sports humanistic sociology from a scientific point of view, and a strong atmosphere of academic research has not yet formed. Since ancient times, any school is established and developed through the contending form. Such academic atmosphere of mutual criticism and debate is conducive to the development of science disciplines. As a result, the team with sports humanities and social sciences disciplines as the core shall be formed nationwide to explore and research the key issues of the discipline, and the outstanding achievements obtained from the research of humanities and social sciences disciplines shall be commended and awarded.

\section{To Achieve Integration of Sports Humanistic Sociology Research and Sports Practice}

The research of sports humanistic sociology should follow the sports practice closely, taking sports practice as the center, regarding the hot and difficult points as well as the problems need to be solved urgently as the important research object. Humanities and social sciences workers should also take the initiative to create conditions by their own, establish and improve joint research in main science and technology of physical practice, so that the study of sports humanistic sociology is more targeted and effective. Second, the sports practice departments shall support the study of sports humanistic sociology, and sports practice departments are required to pay attention to sports humanistic sociology.

\section{CONCLUSION}

This paper analyzes the current situation, problems and strategies of the development of sports humanities and social sciences. In order to develop rapidly, it is necessary to constantly reflect and to solve problems in the course of discovering the problems, only by this, can the discipline value be enhanced, so as to keep with the times.

\section{REFERENCES}

[1] Han Chunli, Cao Li, Sun Jinhai, Wang Qiu. Research on the Current Situation, Problems and Countermeasures of China's Sports Humanistic Sociology.[J] Journal of Beijing Sport University. 2008

[2] Zhai Zhaofeng. Theoretical Paradigm Study on Sports Humanistic Sociology.[D] Master 's Thesis of Qufu Normal University. 2007

[3] Zhang Junxian, Yu Chonggan. Application of Qualitative Research Paradigm in Sports Humanistic Sociology [J].China Sport Science. 2010(10)

[4] Zheng Xiangrong. A Qualitative Study on Current Situation of Sports Humanities Education in Chinese School [A]. Abstract Compilation of the 10th National Sports Science Conference 2015 (1) [C]. 2015 